\title{
Adult scoliosis and non-specific low back pain: analysis of trunk kinematics
}

\author{
L Bissolotti ${ }^{1,3^{*}}$, V Sani ${ }^{1,3}$, M Gobbo ${ }^{2,3}$, C Orizio $^{2,3}$ \\ From 9th International Conference on Conservative Management of Spinal Deformities - SOSORT 2012 \\ Annual Meeting \\ Milan, Italy. 10-12 May 2012
}

\section{Background}

Adult scoliosis (AS) is an emerging issue in the field of spinal deformities management [1]. The increased prevalence results from the cumulative effect due to aging of patients affected by juvenile scoliosis (JS) plus the appearance of new cases in adult age.

\section{Aim}

To provide data about trunk kinematics performance in patients with AS, and to compare it with non-specific low back pain (NL).

\section{Methods}

Cotrel method was used to assess Cobb angle (CA) on plain $\mathrm{x}$-ray. Bilateral trunk side bending $(\mathrm{SB})$ and extension (TE) were evaluated with a two optoelectronic cameras (14markers, Gemini BTS spa, Milano, Italy)[2]. During active range of motion $\left(\mathrm{aROM},{ }^{\circ}\right)$, speed of motion $(\mathrm{SOM}, \% / \mathrm{sec})$ and error in trunk repositioning (ETR, $\left.{ }^{\circ}\right)$ were measured. Patients performed, as allowed by pain or discomfort, two movements for each direction.

\section{Results}

AS-Group included 40 patients (10 men and 30 women, $\mathrm{CA}>15^{\circ}$, age $61.8 \pm 11.5$ years, BMI $\left.23.6 \pm 2.8 \mathrm{~kg} / \mathrm{m} 2\right)$. A single curve was present in 32 patients $(80 \%)$. CA of primary curve averaged $27.1 \pm 11.5^{\circ}$ (range, $15-63^{\circ}$ ), thoracic CA averaged $25.5 \pm 22.3^{\circ}$ (range, $8-58^{\circ}$ ). NL-Group included 40 patients, 9 men and 31 women (age was $58.2 \pm 10.9$ years, BMI $23.9 \pm 3.2 \mathrm{~kg} / \mathrm{m} 2)$. NL-Group averaged $35.7 \pm 12.3^{\circ}$ in aROM on the right side, and $35.2 \pm 11.2^{\circ}$ on the left (SOM $\left.28.1 \pm 13.6^{\circ} / \mathrm{sec}\right)(\mathrm{p}>0.05)$. AS-Group averaged $34.6 \pm 10.6^{\circ}$ of aROM on the right side, and $35.5 \pm 12.5^{\circ}$ on the left side

${ }^{1}$ Servizio di Recupero e Rieducazione Funzionale, Casa di Cura Domus

Salutis, Brescia, Italy

Full list of author information is available at the end of the article
(SOM 31.8 $\left.\pm 11.7^{\circ} / \mathrm{sec}\right)(\mathrm{p}>0.05)$. Global trunk mobility during SB test averaged $71.0 \pm 21.2^{\circ}$ in NL-group and $64.2 \pm 29.1^{\circ}$ in AS-group ( $>>0.05$ ), with no differences when considering the two different directions. During SB, 26\% of the trunk aROM derived from the relative contribution of lumbar segment (L1-L5) (AS vs NL p >0.05). TE averaged $23.7 \pm 8.1^{\circ}$ in NL-Group, (L1-L5: $54.5 \pm 26.3 \%$ ) and $22.6 \pm 8.1^{\circ}$ in AS-Group (L1-L5: 60.8 $\left.\pm 30.6 \%\right)(\mathrm{p}>0.05)$. NL group ETR was $3.4 \pm 2.7^{\circ}$ during $\mathrm{SB}$ and $3.6 \pm 2.0^{\circ}$ during TE (p>0.05). In AS group, ETR was $3.4 \pm 1.5^{\circ}$ during SB and $2.9 \pm 2.0^{\circ}$ during $\mathrm{TE}(\mathrm{p}>0.05)$.

\section{Conclusions}

In an AS-Group of patients, the kinematic performance, and the ability to control spinal motion (SOM and ETR), was similar to a NL-Group. Mild to moderate scoliosis is not influencing the motor control of the spine. As previously shown in NL[3], physiotherapy programs for AS do not require more attention in trunk proprioception.

\begin{abstract}
Author details
${ }^{1}$ Servizio di Recupero e Rieducazione Funzionale, Casa di Cura Domus Salutis, Brescia, Italy. ${ }^{2}$ Sezione di Fisiologia Umana, Dipartimento di Scienze Biomediche e Biotecnologie, Università degli Studi di Brescia, Brescia, Italy. ${ }^{3}$ LARIN: Laboratorio di Riabilitazione Neuromuscolare e Attività Fisica

Adattata, Brescia, Italy.
\end{abstract}

Published: 3 June 2013

\section{References}

1. Aebi M: The adult scoliosis. Eur Spine J 2005, 14(10):925-948.

2. Gombatto SP, Collins DR, Sahrmann SA, Engsberg JR, Van Dillen LR: Patterns of lumbar region movement during trunk lateral bending in 2 subgroups of people with low back pain. Phys Ther 2007, 87(4):441-454.

3. Lee AS, Cholewicki J, Reeves NP, Zazulak BT, Mysliwiec LW: Comparison of trunk proprioception between patients with low back pain and healthy controls. Arch Phys Med Rehabil 91(9):1327-1331.

doi:10.1186/1748-7161-8-S1-032

Cite this article as: Bissolotti et al: Adult scoliosis and non-specific low back pain: analysis of trunk kinematics. Scoliosis 2013 8(Suppl 1):032.

\section{() Biomed Central}

